\title{
Nutrient and food intakes in selected subgroups of Belgian adults
}

\author{
Stefaan De Henauw* and Guy De Backer \\ Department of Public Health, University of Ghent, University Hospital, 2 Blok A, De Pintelaan 185, 9000 Ghent, Belgium
}

\begin{abstract}
In March 1997, official dietary guidelines were for the first time published in Belgium by the National Council on Nutrition. These guidelines are entirely focussed on nutrient intake and do not translate this information into specific 'food-based' recommendations.

In this paper, actual intake data for the adult Belgian population are compared to these guidelines. It is concluded that the overall macronutrient intake pattern in Belgium corresponds to the typical Western so-called affluent diet.

As a next step, an attempt is made to outline a conceptual framework for developing foodbased dietary guidelines on the basis of existing food consumption databases. For that purpose, nutrient and food intake profiles - percentage of consumers and mean intakes for the total population and for consumers only - are studied for subgroups of the population that do or do not comply to predefined dietary goals for total fat intake, fibre intake, and fruit and vegetable intake.

Finally, it is shown with an example that these data can be used as a basis for formulating healthy food recommendations towards the general population in terms of specific foods or food groups to be avoided or to be chosen preferably.

The food and nutrient intake data used in this paper are from the BIRNH study (Belgian Interuniversity Research on Nutrition and Health, 1980-1984), the only nationwide food consumption survey on an individual level ever carried out in Belgium.
\end{abstract}

\section{Dietary guidelines: Food based: Belgium}

Belgium has a complex political structure, in which the federal government as well as the regional governments (for Flanders in the north, Wallonia in the south and the Brussels capital region in the centre) have their own specific powers in the field of (among others) public health.

Health-promoting campaigns in the field of nutrition have to date only been undertaken on a regional level. In the Dutch-speaking region of Flanders, a widespread campaign on 'fibre-rich' foods was launched in 1996. Through mass media communications, the general population was encouraged to eat more wholegrain cereals, potatoes, fruits and vegetables. However, the effect of this campaign has not yet been measured. More recently - since September 1997 - a healthy-eating promotion campaign has been developed in Flanders, basically based on the food guide pyramid model (US Department of Agriculture, 1992). In the French-speaking region of Wallonia, a number of health-promotion campaigns regarding nutrition have also been carried out over the last years, mostly focussing on schools and school medical services.

It was only very recently - March 1997 - that dietary guidelines were for the first time in Belgium formulated on a national level by the National Council on Nutrition, and published by the Ministry of Health in Dutch, French and
German (National Council on Nutrition, 1997). The National Council on Nutrition is embedded in the Council on Public Health - a scientific body, which advises the federal authorities on public health issues. The Belgian dietary guidelines are to a large extent adopted from neighbouring countries and from supranational bodies like the WHO or the European Union. In general, the recommended dietary allowances for nutrients, formulated in the Belgian guidelines, are based on the principle of the socalled 'population reference intake' (PRI), whereby the recommended value is chosen as the average requirement in the population plus two standard deviations (Commission of the European Communities, 1993). Energy requirements are elaborated in detail in the guidelines for different strata of gender, age and physical activity level.

In Table 1a, the most important guidelines for the adult population are summarized for macronutrients. These guidelines parallel strongly the recommendations published by a WHO Working Group in 1990 (World Health Organization, 1990). For total fat intake (in energy\%) the conservative cut-off point of $30 \%$ as an upper limit has been put forward as a population average. Within the group of carbohydrates, it is recommended to moderate the intake of 'added sugars'. In general, separate recommendations are

\footnotetext{
*Corresponding author: Dr Stefaan De Henauw, fax +32 924049 94, email stefaan.dehenauw@ @ug.ac.be
} 
Table 1a. Dietary guidelines as population average for adults ( $>18$ years) regarding macronutrients as formulated by the Belgian Council on Nutrition

(in percent of energy unless specified otherwise)

\begin{tabular}{lccc}
\hline & Lower limit & Upper limit \\
\hline Protein & \multicolumn{3}{c}{ About 10\% of energy } \\
Total fat & 15 & & 30 \\
Saturated fatty acid & 0 & 10 \\
Polyunsaturated fatty acid & 3 & 7 \\
Monounsaturated fatty acid & No specific recommendation (total fat - (sfa + pufa)) & 75 \\
Total carbohydrate & 55 & & - \\
Complex carbohydrate & 50 & To be moderated & \\
Added sugar & 15 & & 22 \\
Dietary fibre $(\mathrm{g} / 1000 \mathrm{Kcal}$ per day) & 0 & & 300 \\
Dietary cholesterol $(\mathrm{mg} / \mathrm{d})$ & & \\
\hline
\end{tabular}

given for the population below 18 years of age. No recommendations on fibre intake are given for children and adolescents, due to 'insufficient scientific evidence'.

In the official Belgian dietary guidelines, recommendations are given only in terms of nutrients and not in terms of foods or food groups. However, in the healthy-eating promotion campaign in Flanders, specific recommendations for food groups were given on the basis of the food guide pyramid model. In this campaign, the lower limit for the daily intake of fruit and vegetables is given at 200 and $300 \mathrm{~g}$ respectively. For meat and fish, an upper limit of $100 \mathrm{~g} / \mathrm{d}$ is specified; for milk a lower limit of about $500 \mathrm{ml} / \mathrm{d}$ and for milk products a recommended range of 20 to $40 \mathrm{~g}$ daily. Further recommendations are 5-12 slices of wholegrain bread and 3-5 potatoes daily. In this same campaign, some general 'healthy-eating tips' and 'health tips' are also given to the general population; these tips are listed in Table $1 \mathrm{~b}$.

In this paper, actual intakes for the adult Belgian population are compared to dietary guidelines. Furthermore, nutrient and food intake profiles are studied for subgroups of the population selected on the basis of their position in the overall distribution for the intake of specific nutrients and foods.

\section{Methods}

The data presented in this paper originate from the only nationwide dietary survey that has ever been carried out in Belgium on individual level - the BIRNH study (Belgian Interuniversity Research on Nutrition and Health). The methodology and the most important results of this study have been published elsewhere (De Backer, 1984; Kornitzer \& Bara, 1989). In brief, 11302 males and females aged 2574 years were screened between 1980 and 1985 for diet and cardiovascular risk factors. The participation rate was $36.5 \%$. Participants were selected randomly from the voting lists in 42 out of a total of 43 Belgian districts. The primary objective in BIRNH was to study the association between nutrition and total and cause-specific mortality in an ecological design (De Backer, 1984).

Dietary habits were assessed on the basis of a $24 \mathrm{~h}$ estimated food record method. Participants were asked to record everything they ate or drank over a 24-hour period in an open-ended food diary. Food records were checked on quality and completeness by trained dieticians and then quantified and coded into 156 food groups. Nutrients were calculated using a self-developed nutritional software, based on the Dutch Food Composition Tables (Nutrition Information Centre, 1979), on the food composition tables developed by Paul \& Southgate (1980) and on food composition data available in Belgium for particular food items (e.g. certain margarines). Entries for food items in the BIRNH study are in general highly aggregated. Only 17 entries are available for meat and meat products, 12 for dairy products and 7 for cereals. In contrast, data on fruit and vegetables are available on a more individual level.

For the purpose of identifying nutrient- and food-intake profiles in subfractions of the population that do or do not comply to predefined dietary goals, the intake of nutrients and foods has been calculated for the upper and lower quartile for total fat intake, fibre intake, and fruit and vegetable intake. The decision on which foods to include in these analyses was partly based on calculations concerning the foods that contribute largely ( $\geq 90 \%)$ to the intake of fat (Staessen et al. 1998) and fibre (unpublished data) on a population level, and partly also on general considerations of the importance of specific foods in the general context of a healthy diet within the specific cultural context of Belgium. As it is impossible to show the analyses for all strata that were used for gender and age, results are shown alternatively for different age and sex groups (Tables 35). Non-parametric statistical tests (Mann-Whitney) were used to study differences between upper and lower quartile fractions of the population in nutrient and food item intake.

Table 1b. 'Healthy-eating tips' and 'health tips' as formulated in the Flemish healthy-eating promotion campaign

\begin{tabular}{|c|c|}
\hline Healthy-eating tips & Health tips \\
\hline $\begin{array}{l}\text { * Eat a variety of foods } \\
\text { * Eat lots of vegetables, fruit, potatoes and wholegrain cereals } \\
\text { * Moderate on meat, fat, sugar and salt } \\
\text { * Drink a lot of water and milk products } \\
\text { * Eat on a regular basis and not more than } 5 \text { times } / \mathrm{d}\end{array}$ & $\begin{array}{l}\text { * Take sufficient time for your meals } \\
\text { * Wash your hands before eating or preparing foods } \\
\text { * Read the information on food packages } \\
\text { * Watch your weight } \\
\text { * Take some physical activity regularly }\end{array}$ \\
\hline
\end{tabular}


Table 2. Actual intake of selected nutrients and foods in Belgian males and females aged 25-74 years vis à vis dietary guidelines (in \%energy unless specified otherwise)

\begin{tabular}{|c|c|c|c|c|c|}
\hline & \multirow[b]{2}{*}{ Recommended } & \multicolumn{2}{|c|}{ Males } & \multicolumn{2}{|c|}{ Females } \\
\hline & & mean (SD) & median & mean (SD) & median \\
\hline Protein & $10-15 \%$ & $13 \cdot 3(3 \cdot 3)$ & $12 \cdot 9$ & $14.5(3.9)$ & $13 \cdot 8$ \\
\hline Total fat & $<30 \%$ & $41.8(8.4)$ & $42 \cdot 1$ & $42.6(8.3)$ & $43 \cdot 0$ \\
\hline SFA & $<10 \%$ & $17 \cdot 3(5 \cdot 0)$ & $17 \cdot 3$ & $17.6(4.9)$ & $17 \cdot 6$ \\
\hline PUFA & $<3-7 \%$ & $7.6(4.5)$ & 6.6 & $7.8(4.6)$ & $6 \cdot 8$ \\
\hline MUFA & - & $15 \cdot 2(4 \cdot 1)$ & $15 \cdot 1$ & $15 \cdot 4(4 \cdot 1)$ & $15 \cdot 3$ \\
\hline Total carbohydrate & $55-75 \%$ & $38.7(8.0)$ & 38.5 & $39.8(8.2)$ & 39.6 \\
\hline Complex carbohydrate & $\geq 50 \%$ & $24.4(6.3)$ & 24.3 & $23.0(6.1)$ & $22 \cdot 9$ \\
\hline Cholesterol (mg/d) & $<300$ & $433.1(292.5)$ & $357 \cdot 8$ & $346.1(241.6)$ & 283.8 \\
\hline Alcohol & $0 \%$ & $5 \cdot 2(7 \cdot 3)$ & 2.5 & $2.0(4.0)$ & 0.0 \\
\hline Fibre (g/1000 Kcal per day) & $15-22$ & $8.4(3.5)$ & 7.9 & $9.2(3.8)$ & 8.6 \\
\hline Vegetables (g/d) & $>300$ & $138.5(164.7)$ & $200 \cdot 0$ & $172.4(163.7)$ & 194.0 \\
\hline Fruit $(g / d)$ & $>200$ & 206.9 (137.9) & $120 \cdot 0$ & $204.5(131.7)$ & $140 \cdot 0$ \\
\hline
\end{tabular}

SFA = saturated fatty acid; PUFA = polyunsaturated fatty acid; MUFA = monounsaturated fatty acid.

\section{Results}

Table 2 shows actual intakes vis-à-vis dietary guidelines in Belgian males and females aged 25-74 years. Total and saturated fat intake (in energy\%) exceeds the recommended intake by more than $30 \%$ in both men and women. This excess in fat intake is - on average - accompanied by a low carbohydrate intake, which falls $25 \%$ below the

Table 3. Mean daily nutrient and food intake of Belgian males $25-45$ years with low $(n=555)$ and high $(n=590)$ relative fat intake

\begin{tabular}{|c|c|c|c|c|c|c|c|c|}
\hline & \multicolumn{2}{|c|}{ All subjects } & $P$ & \multicolumn{4}{|c|}{ Consumers only } & $P$ \\
\hline $\begin{array}{l}\text { Energy } \\
\text { Protein (\%energy) } \\
\text { Carbohydrate (\%) } \\
\text { Alcohol (\%) } \\
\text { Total fat }(\%) \\
\text { SFA (\%) } \\
\text { MUFA (\%) } \\
\text { PUFA (\%) } \\
\text { Fibre (g/d) }\end{array}$ & $\begin{array}{r}2895 \\
13.5 \\
43.7 \\
10.9 \\
31.0 \\
12.7 \\
11.2 \\
5.7 \\
24.5\end{array}$ & $\begin{array}{r}3368 \\
12 \cdot 8 \\
31.7 \\
3.1 \\
51.9 \\
21 \cdot 3 \\
19.2 \\
9.6 \\
22.6\end{array}$ & $\begin{array}{l}* * * \\
* * \\
* * * \\
* * * \\
* * * \\
\star * * \\
* * * \\
* * * \\
* * *\end{array}$ & $74 \cdot 4$ & & $56 \cdot 4$ & & \\
\hline $\begin{array}{l}\text { Wholemeal bread } \\
\text { Other bread } \\
\text { Pasta/rice/flours } \\
\text { Potatoes }\end{array}$ & $\begin{array}{r}86 \cdot 7 \\
128 \cdot 7 \\
20 \cdot 6 \\
286 \cdot 7\end{array}$ & $\begin{array}{r}69.2 \\
119.5 \\
7.4 \\
342.9\end{array}$ & $\begin{array}{c}* \\
* \\
* * * \\
* * *\end{array}$ & $\begin{array}{l}42 \cdot 2 \\
67 \cdot 9 \\
40 \cdot 2 \\
86 \cdot 1\end{array}$ & $\begin{array}{r}205 \cdot 7 \\
180 \cdot 3 \\
51 \cdot 3 \\
332 \cdot 9\end{array}$ & $\begin{array}{l}32 \cdot 0 \\
75 \cdot 4 \\
30 \cdot 7 \\
91 \cdot 9\end{array}$ & $\begin{array}{r}216 \cdot 0 \\
184 \cdot 5 \\
24 \cdot 2 \\
373 \cdot 3\end{array}$ & $\begin{array}{l}\text { NS } \\
\text { NS } \\
\star \star \star \\
\star \star \star\end{array}$ \\
\hline $\begin{array}{l}\text { Fresh meat } \\
\text { Processed meat } \\
\text { Eggs } \\
\text { Fish }\end{array}$ & $\begin{array}{r}157 \cdot 4 \\
21 \cdot 1 \\
16 \cdot 1 \\
19 \cdot 7\end{array}$ & $\begin{array}{r}183 \cdot 8 \\
80.4 \\
21 \cdot 2 \\
14 \cdot 4\end{array}$ & $\begin{array}{c}* * * \\
* * * \\
* \\
N S\end{array}$ & $\begin{array}{l}82 \cdot 9 \\
32 \cdot 8 \\
29 \cdot 4 \\
18 \cdot 4\end{array}$ & $\begin{array}{r}189.9 \\
64.2 \\
54.8 \\
106 \cdot 9\end{array}$ & $\begin{array}{l}85 \cdot 6 \\
55 \cdot 9 \\
39 \cdot 8 \\
14 \cdot 2\end{array}$ & $\begin{array}{r}214 \cdot 7 \\
143 \cdot 8 \\
53 \cdot 2 \\
101 \cdot 1\end{array}$ & $\begin{array}{l}* * * \\
* * * \\
N S \\
N S\end{array}$ \\
\hline $\begin{array}{l}\text { All fruit } \\
\text { Pulses } \\
\text { Other vegetables }\end{array}$ & $\begin{array}{r}157.7 \\
0.9 \\
221.6\end{array}$ & $\begin{array}{r}106.3 \\
0.4 \\
211.5\end{array}$ & $\begin{array}{l}* * * \\
\text { NS } \\
\text { NS }\end{array}$ & $\begin{array}{r}59.6 \\
2.0 \\
91.9\end{array}$ & $\begin{array}{r}264.4 \\
49 \cdot 8 \\
241 \cdot 1\end{array}$ & $\begin{array}{r}49.8 \\
0.7 \\
92.9\end{array}$ & $\begin{array}{r}213 \cdot 3 \\
71 \cdot 7 \\
227 \cdot 7\end{array}$ & $\begin{array}{l}* * * \\
N S \\
N S\end{array}$ \\
\hline $\begin{array}{l}\text { Margarine; Low P/S } \\
\text { Margarine; High P/S } \\
\text { Butter }\end{array}$ & $\begin{array}{r}14 \cdot 9 \\
7 \cdot 4 \\
17 \cdot 7\end{array}$ & $\begin{array}{r}22 \cdot 3 \\
8 \cdot 7 \\
30 \cdot 4\end{array}$ & $\underset{* *}{* * *}$ & $\begin{array}{l}52 \cdot 6 \\
23 \cdot 8 \\
51 \cdot 0\end{array}$ & $\begin{array}{l}28.5 \\
31 \cdot 0 \\
34 \cdot 8\end{array}$ & $\begin{array}{l}59 \cdot 5 \\
22 \cdot 2 \\
59.5\end{array}$ & $\begin{array}{l}37 \cdot 4 \\
39 \cdot 1 \\
51 \cdot 0\end{array}$ & $\begin{array}{l}* * * \\
* * \\
* * *\end{array}$ \\
\hline
\end{tabular}

SFA: saturated fatty acids; PUFA: polyunsaturated fatty acids; MUFA: monounsaturated fatty acids; Cons: consumers; Low P/S: low ratio of polyunsaturated to saturated fatty acids; High $\mathrm{P} / \mathrm{S}$ : high ratio of polyunsaturated to saturated fatty acids; ${ }^{\star} P<0.05 ;{ }^{\star *} P<0.01 ;{ }^{\star \star \star} P<0.001$. 
Table 4. Mean daily nutrient and food intake of Belgian males aged 25-74 years with low $(n=1457)$ and high $(n=1452)$ fibre intake

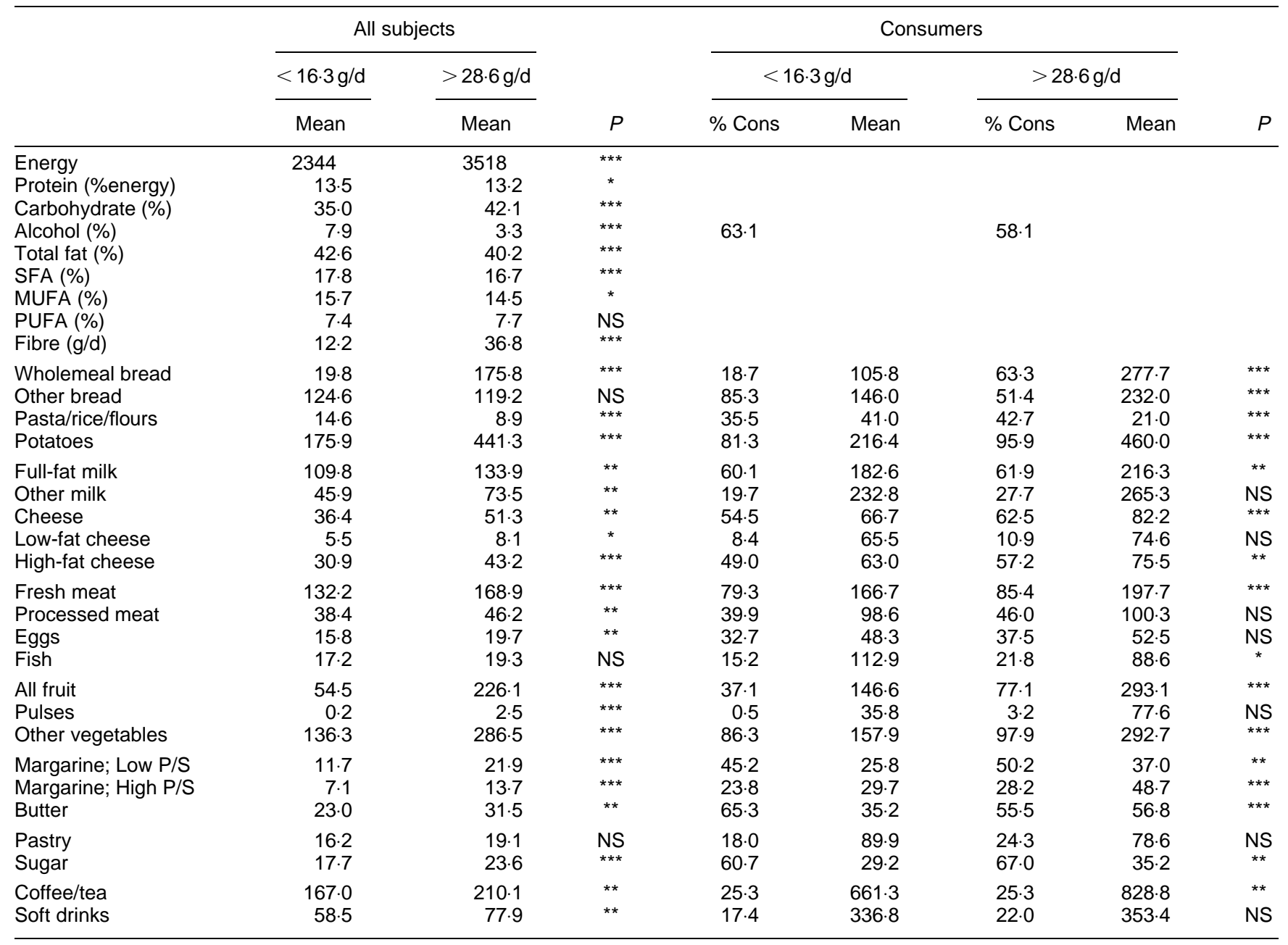

SFA: saturated fatty acids; PUFA: polyunsaturated fatty acids; MUFA: monounsaturated fatty acids; Cons: consumers; Low P/S: low ratio of polyunsaturated to saturated fatty acids; High P/S: high ratio of polyunsaturated to saturated fatty acids; ${ }^{\star} P<0.05 ;{ }^{\star \star} P<0.01 ;{ }^{\star \star \star} P<0.001$.

recommended intake. Fibre intake is about half of the recommended intake and this is reflected in a fruit and vegetable intake far below recommendations.

Table 3 shows mean daily nutrient and selected food intake in Belgian males aged 25-45 years with total fat intake (in energy\%) below and above the lower and upper quartile respectively, separately for the total population and for - as far as foods are concerned - consumers only. People from the lowest quartile of total fat intake had a substantially higher carbohydrate and fibre intake and a lower intake for all categories of fat. Remarkably, they also had a threefold alcohol intake (in energy\%) as compared to high fat consumers. People from the highest quartile of total fat intake had in general significantly higher intakes of potatoes, highfat cheese, fresh meat, spreading fat (especially butter) and pastry, and a significantly lower intake of low-fat milk, fruit, vegetables, sugar and soft drinks. In the highest quartile of total fat intake, a significantly higher percentage of consumers was observed for processed meat and a significantly lower percentage of consumers for low-fat milk and fruit. Similar results were observed also for older males and for females (data not shown).
Table 4 shows mean daily nutrient and selected food intake in Belgian males aged 25-74 years with fibre intake (in energy\%) below and above the lower and upper quartile respectively, separately for the total population and for - as far as foods are concerned - consumers only. People from the lower quartile of fibre intake had a substantially lower relative carbohydrate intake and a higher relative alcohol intake. Differences in total fat intake were - although statistically significant - not very large.

People from the higher quartile of fibre intake had a significantly higher intake of wholemeal and other bread, potatoes, full-fat milk, high-fat cheese, fresh meat, butter and fruit and vegetables; and a lower intake of pasta, rice and fish. In the highest quartile of fibre intake, a higher percentage of consumers was observed for wholemeal bread and fruit and a lower percentage of consumers for other types of bread. Similar results were also observed in women.

Table 5 shows mean daily nutrient and selected food intake in Belgian females aged 25-74 years with fruit and vegetable intake below and above the lower and upper quartile respectively, separately for the total population and for - as far as foods are concerned - consumers only. 
Table 5. Mean daily nutrient and food intake of Belgian females aged 25-74 years with low $(n=1316)$ and high $(n=1319)$ fruit and vegetable intake

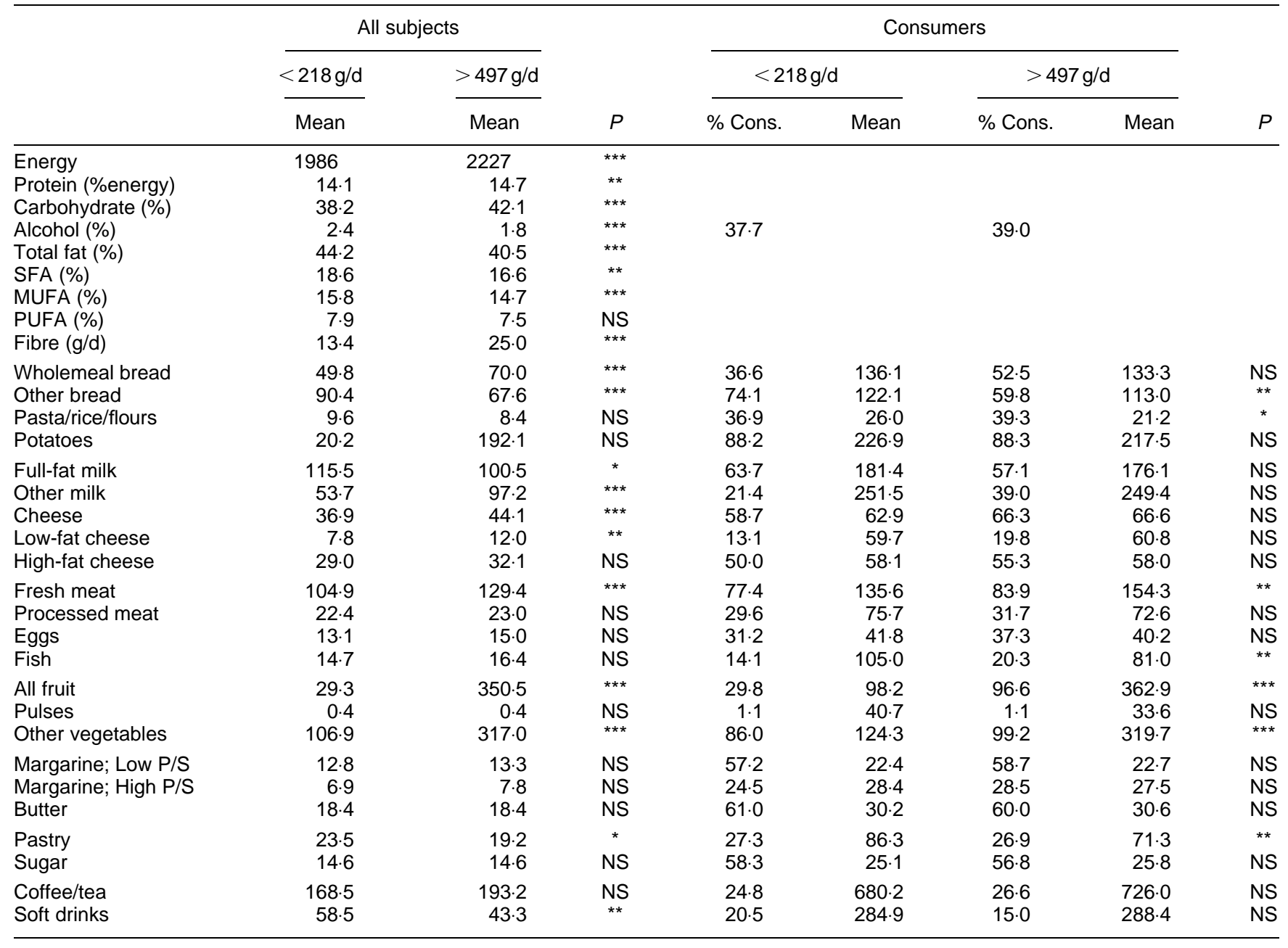

SFA: saturated fatty acids; PUFA: polyunsaturated fatty acids; MUFA: monounsaturated fatty acids; Cons.: consumers; Low P/S: Low ratio of polyunsaturated to saturated fatty acids; High $\mathrm{P} / \mathrm{S}$ : High ratio of polyunsaturated to saturated fatty acids; $P<0.05 ;{ }^{\star \star} P<0.01 ;{ }^{\star \star \star} P<0.001$.

People from the lowest quartile of fruit and vegetable intake had significantly lower relative carbohydrate intake and a significantly higher relative fat intake. Consumers of high amounts of fruit and vegetables have also a significantly higher intake of fresh meat, and a significantly lower intake of pasta, rice, fish, pastry and soft drinks. The fraction of the population with the highest intake of fruit and vegetables also has the highest percentage of consumers for these foods. Similar results were also observed for men.

\section{Discussion}

In this paper, nutrient and food intake profiles are presented for subgroups of the general population with low and high (relative) intake of total fat, fibre, and fruit and vegetables on the basis of data from the BIRNH study, the only nationwide food consumption survey carried out in Belgium so far. These results can be used as a starting point for elaboration of food-based instead of nutrient-based dietary guidelines.

A number of methodological aspects need to be highlighted, though. The BIRNH data go back to the early 1980s and therefore do not necessarily represent the actual situation on nutrient and food intake in the Belgian population. Between then and now a lot of changes have taken place in the availability of foods, both quantitatively and qualitatively. Moreover, the participation rate in BIRNH was very low $(36.5 \%)$ and therefore the sample doesn't necessarily represent the total population. Data on food items are highly aggregated in the BIRNH database. This means an important loss of information that could have been very useful in the context of developing dietary guidelines based on individual foods and food groups. In BIRNH, a $24 \mathrm{~h}$ estimated food record method was used. This method is known to give good estimates for central measures of intake distribution, but at the same time overestimation of the extremes at both sides of the distribution (Willett, 1990). Therefore, an important degree of misclassification of individuals vis-à-vis the upper and lower quartile of intake can have occurred. From Table 2, it can be concluded that the overall macronutrient intake pattern in Belgium corresponds very well to the typical Western so-called 'affluent' diet, characterized roughly by an excessive 
intake of saturated fatty acids and a poor intake of complex carbohydrates, fibre, and fruit and vegetables.

Taking into account methodological shortcomings, the food consumption profile in the upper and lower quartiles of the selected nutrient and food intake distribution gives some clues towards the development of food-based dietary guidelines, although it would probably be better for this purpose to combine the four items (total fat, saturated fat, fibre, and fruit and vegetables) and to study individuals who are at the upper and lower ends of the distribution for all these items. Though people above the higher quartile of fat intake may well be the same as those above the higher quartile for saturated fat, they could be - at least partly different from those above the higher quartile for fibre or fruit and vegetable intake.

Improvement in nutrient intake can generally be achieved in different ways: changing the percentage of consumers of foods that can substantially contribute to the intake of the nutrient of interest; increasing the frequency of intake; increasing the portion sizes; and shifting to an alternative food item with a substantially different content of the nutrient of interest. The data presented in this paper give information on the percentage of consumers and on the mean intake of foods as a resultant of the frequency of intake and the portion sizes. Therefore, these data can be used as a basis for formulating healthy food recommendations towards the general population in terms of specific food items to be avoided or to be recommended. As an example, from Table 4 we know that the percentage of consumers of wholemeal bread in low fibre consumers is much lower and that the portion sizes are moreover much smaller as compared to high fibre eaters. The same table also indicates, however, that high-fibre eaters have a significantly higher intake of meat and butter. Therefore, we conclude that substantial improvement in fibre intake can potentially be obtained, but should go hand in hand with recommendations on moderation of meat and butter as apparently - the increased intake of wholemeal bread is not automatically accompanied by a decrease in meat and butter intake.

\section{References}

Commission of the European Communities (CEC) (1993) Nutrient and energy intakes for the European Community. Reports of the Scientific Committee for Food (thirty-first series), Brussels.

De Backer G, on behalf of the BIRNH Study Group (1984) Regional differences in dietary habits, coronary risk factors and mortality rates in Belgium. Design and methodology. An interuniversity study. Acta Cardiologica 39, 285-292.

Kornitzer M \& Bara L, on behalf of the BIRNH Study Group (1989) Clinical and anthropometric data, blood chemistry and nutritional patterns in the Belgian population according to age and sex. Acta Cardiologica 44, 101-111.

National Council on Nutrition (Nationale raad voor de Voeding) (1997) Dietary recommendations for Belgium (Voedingsaanbevelingen voor België). Ministry of Social affairs, Public Health and Environment (publication D/1996/7795/12), Brussels.

Nutrition Information Centre (1979) Dutch food composition table. Voorlichtingsbureau voor de voeding, Den Haag.

Paul AA \& Southgate DAT (1980) The composition of foods, 4th ed., revised. Report No. 297. London: MCR.

Staessen L, De Henauw S, De Bacquer D, De Backer G \& Van Peteghem C (1998) Fat sources in the Belgian diet. Annals of Nutrition and Metabolism 42, 138-150.

US Department of Agriculture (1992) The food guide pyramid. Hyattsville, MD: Human Nutrition Information Service (Publication HG252).

WHO (World Health Organization) (1990) Diet, nutrition and the prevention of chronic diseases. Technical report series 797. Geneva: WHO.

Willett W (1990) Nature of variation in the diet. In Nutritional Epidemiology. Monographs in Epidemiology and Biostatistics, Vol 15, pp. 35-51 [W Willett, editor]. Oxford: Oxford University Press. 